\title{
Schneider, Jens, Auf der Suche nach dem verlorenen Reich. Lotharingien im 9. und 10. Jahrhundert
}

\author{
Charles Mériaux
}

\section{OpenEdition}

\section{Journals}

Édition électronique

URL : http://journals.openedition.org/ifha/2172

DOI : $10.4000 /$ ifha. 2172

ISSN : 2198-8943

Éditeur

IFRA - Institut franco-allemand (sciences historiques et sociales)

Référence électronique

Charles Mériaux, «Schneider, Jens, Auf der Suche nach dem verlorenen Reich. Lotharingien im 9. und 10 Jahrhundert », Revue de l'IFHA [En ligne], Date de recension, mis en ligne le 01 janvier 2010, consulté le 22 septembre 2020. URL : http://journals.openedition.org/ifha/2172 ; DOI : https://doi.org/10.4000/ ifha. 2172

Ce document a été généré automatiquement le 22 septembre 2020.

(C)IFHA 


\title{
Schneider, Jens, Auf der Suche nach dem verlorenen Reich. Lotharingien im 9. und 10. Jahrhundert
}

\author{
Charles Mériaux
}

1 Effectué en 843, le partage de Verdun - suivi de l'adoption par les différents royaumes de nouveaux souverains en 887-888 - est souvent considéré comme l'acte de naissance des nations européennes. Le sort de la Francie médiane, et plus particulièrement de sa partie septentrionale gouvernée par Lothaire II de 855 à 869, la Lotharingie, reste une énigme. Ancré au cœur du monde carolingien, ce royaume n'a pas véritablement connu d'existence autonome après la mort de Lothaire II, sauf pendant les courtes années du règne de Zwentibold (895-900). En 925, il devint un duché du royaume de Germanie. Convoitée au Xe siècle par les Carolingiens de Francie occidentale, la Lotharingie cessa néanmoins d'être un enjeu disputé avec l'avènement d'Hugues Capet en 987.

Dans une thèse de doctorat soutenue en juin 2008 et préparée sous la double direction des professeurs Régine Le Jan (Université de Paris 1) et Jörg Jarnut (Université de Paderborn), J.S. s'empare à son tour d'un dossier à la bibliographie déjà très riche. Dans ce champ d'étude bien balisé par les études de Robert Parisot, d'Eduard Hlawitschka, de Bernd Schneidmüller et de Michel Parisse, son livre apporte indiscutablement du nouveau, tant par la méthode que par les résultats. L'auteur développe en effet l'étude d'un ensemble de «marqueurs » qui pourraient rendre compte de l'émergence d'une identité proprement lotharingienne aux IXe-XIe siècles : la géographie physique, les héritages historiques, la démographie, l'économie, la production diplomatique, les pratiques des réseaux aristocratiques. Il montre que cette identité, supposée par de nombreux historiens en particulier sous la forme d'une continuité avec l'Austrasie mérovingienne et pippinide, est une fiction. J.S. part moins à la recherche d'un " royaume perdu " qu'il ne récuse l'idée selon laquelle celui-ci aurait connu une consistance propre, si éphémère fût-elle. D'autre part, à la suite de travaux désormais nombreux sur le rôle de la construction du passé dans l'élaboration des identités politiques du haut Moyen Âge, l'auteur montre l'absence d'une entreprise de ce type 
dans les milieux lotharingiens. Il s'appuie sur ce constat : les Lotharingiens ne se sont jamais désignés eux-mêmes de la sorte. Le nom du royaume et celui de ses habitants ont été forgés de l'extérieur. En soulignant le désintérêt des grands centres monastiques pour une historiographie proprement lotharingienne, J.S. mène une réflexion très neuve qui se fonde sur des sources peu exploitées jusque là par les historiens : dans le fil de ses premiers travaux sur l'écolâtre Otfrid de Wissembourg ( $\dagger$ après 870 ), il étudie la production littéraire en langue vernaculaire des monastères de Saint-Amand et de Wissembourg, certes l'un et l'autre extérieurs à la Lotharingie, mais très liés aux grandes familles lotharingiennes. Prolongeant une idée développée par Régine Le Jan, J.S. soutient qu'aux IXe-Xe siècles, la Lotharingie ne s'est jamais autrement pensée que comme le cœur du monde franc unitaire. En somme, elle doit surtout être considérée comme « une idée des historiens modernes » (p. 484).

3 Le livre s'achève sur un riche dossier d'annexes : édition et traduction du Rithmus Teutonicus célébrant la victoire de Louis III sur les Normands, liste des textes " lotharingiens » en langue vulgaire, catalogues reprenant les actes lotharingiens des IXe-Xe siècles, tableau des établissements ecclésiastiques. Signalons enfin les services que rendra un résumé français développé (p. 465-484).

Charles Mériaux (Université Lille III) 